\section{Reduction of Road Accidents}

IN view of the increasing attention which is being directed to road accidents and their causes and prevention, a pamphlet recently issued by the National Institute of Industrial Psychology dealing with practical methods for reducing accidents and transport costs is worthy of general attention. The difficulty of ascertaining accurately the ability of a driver is widely realised, but the way in which his accident record may be misleading and lead to unfair judgments of his abilit $J$ is less well known. As a result of a considerable amount of research, the Institute has now been able to devise and standardise a group of psychological tests which can be applied to select the best drivers from among a group of applicants for a post. The results of the tests have shown a remarkable concordance with estimates based on close observation of actual driving performance. The tests are equally valuable for selecting the men most suitable for training as drivers and they can also be applied to discover what is lacking in drivers of poor ability in order to remedy deficiencies where possible. A fourth direction of application is of even wider interest as the tests can be used to advise those who intend to learn to drive as to what degree of ability they are likely to develop after adequate tuition and experience. The bearing of such tests on the prevention of road accidents is obvious. The Institute's fee for carrying out such a test is two guineas.

\section{Quarterly Journal of Experimental Physiology}

Vou. 23 of the Quarterly Journal of Experimental Physiology is dedicated by his past and present assistants to Sir Edward Sharpey-Schafer, in honour of his eighty-third birthday. It contains thirty-one papers, which have been collected and edited by Dr. Argyll Campbell and Sir Leonard Hill, two of his former assistants. The list of those who have participated in the production of the volume contains twenty-nine names, covering a period of nearly fifty years. It is unnecessary to mention the great advances made by physiology in this time, advances to which Sir Edward Sharpey-Schafer has himself in no small degree contributed. In the present volume, the original contributions cover many different aspects of physiological science, from the effects of posture on heart-rate and blood pressure and the discomfort of close rooms caused by infra-red rays, to studies on arginase, the effect of formaldehyde on vitamin $B_{1}$ and variations of the anterior pituitary hormone in the blood in pregnancy, to mention only a few. Examination of the volume gives a good idea of the branches of physiology in which interest is being taken at the present time and indicates that this science is rapidly adding to our store of knowledge.

\section{A 'Sun-Path Demonstrator}

Teachers who have difficulty in explaining geographical and astronomical phenomena which involve motion in three dimensions may find that a model illustrating the phenomenon is much more intelligible to the pupil than is any blackboard drawing intended to represent three dimensions.
Messrs. Philip and Son, Ltd,, 32, Fleet Street, London, E.C.4, have sent to NATURE office a model called the "Sun-Path Demonstrator" (price 15s.) the use of which is to demonstrate the sun's apparent motion, hour by hour, at the equinox and solstices, as it appears to an observer in any latitude. The latitude can be set by one protractor and the sun's altitude read off on another protractor. The device may be helpful in demonstrating the particular point, but why the sun should behave in this way is left quite unexplained. Nevertheless, a wide acquaintance with such a device would tend to lessen the number of otherwise intelligent pupils who find particular difficulty with problems of this nature.

\section{Early Man in Nevada}

FURTHER evidence of the presence of early man in the United States, which is regarded as "highly suggestive if not absolutely convincing", is reported by Dr. George Gaylord, of the American Museum of Natural History, to have been found in Nevada, according to a statement issued by Science Service, Washington, D.C. This is a flake of obsidian found by a field party led by Mr. Fenley Hunter while quarrying for the bones of fossil animals. It was enclosed in an undisturbed matrix in a horizon in which were the remains of camel, horse and deer, and belonging to Pleistocene or post-Pleistocene times. The flake bears marks of chipping, as for the preparation of a blade. Obsidian has not been found in the region of the discovery, this fact strengthening the view that the flake is of human origin. Charcoal is stated also to have been found in three well-defined areas, and is presumed to be the remains of ancient hearths.

\section{Index Veterinarius}

WE have received the first number of the Index Veterinarius (vol. 1, No. 1. April 1933), the proposed publication of which by the Imperial Bureau of Animal Health has been mentioned in these columns, and covers the first quarter of this year. It is a volume, produced by duplicator, of 304 pages, preceded by 36 pages of explanatory introduction and the list of journals and reports indexed, with key to the abbreviations adopted. The Index will be issued quarterly, and each volume will be a single complete alphabetical index of veterinary publications, authors' names and subjects being given their appropriate places in the same series; references are fully cross-indexed under subject headings. The publication should be of great service to the veterinary profession and to research workers on veterinary subjects. The annual subscription is $\mathfrak{£} 4$, which should be forwarded to the Bureau, Weybridge, Surrey, England.

\section{Irritating References}

DR. F. A. BATHER recently complained (NATURE, July 15) of the irritation and loss of time caused by the custom of not indicating the page number of a new chapter. Mr. C. A. Silberrad, 2 Forrest Side, Epping, Essex, writes to say that a far greater source of irritation and loss of time is the habit of many 
authors of giving a reference as "loc. cit. p._-", with no indication as to where the previous reference has been given-often several pages previously. He adds : "Surely it should be generally recognised that 'loc. cit.' is not to be used unless the previous reference is on the same page as the second reference."

\section{Medical Uses of Radium}

UNDER this title, the Medical Research Council has issued a summary of reports from radium research centres for 1932 (Special Rep. Series, No. 186. H.M. Stationery Office. 1s. net). Brief details of the results obtained during the year are given, as well as a statistical analysis of data relating to the after-histories of patients treated in earlier years. The treatment of cancer of the rectum by irradiation, hitherto disappointing, appears now to have a more favourable future as a result of better understanding of the dosage.

\section{Victorian Bush Nursing Association}

The Bush Nursing Hospitals, Victoria, Australia, of which we have received the annual report to June 1933, are apparently furnishing the solution to the problem of medical attendance in the country. They are owned and controlled by the centres, and are available to all who need them at fixed rates. They enable cases of illness to be dealt with which otherwise would have to be sent many miles for treatment.

\section{The Leonids, 1933}

BAD weather in mid-November seems to have precluded most of the English observers from watching for the return of the Leonid shower this year. Mr. A. King, of Scunthorpe, Lincs, however, was able to maintain a lookout on November 16 (the probable night of maximum), from $9 \mathrm{~h}$. $55 \mathrm{~m}$, to $15 \mathrm{~h}$. $55 \mathrm{~m}$. (G.M.A.T.). There was frequent interruption from cloud and rain, the total time spent in actual watching being $2 \mathrm{~h} .34 \mathrm{~m}$. There were some very clear intervals, and it was evident from the scarcity of meteors that no great shower was in play; indeed, Leonids were not so numerous nor so bright as on November 16 , 1931. The following radiant of Leonids was determined :

$$
\text { Nov. } 16^{\mathrm{d} \cdot 6} \quad 151^{\circ} \cdot 8+21^{\circ} \cdot 8 \quad 7 \text { paths }
$$

Mr. M. A. R. Khan, at Hyderabad, India, notes : “This year's Leonids were a poor show." He observed as under :

\begin{tabular}{|c|c|c|}
\hline Date & Time (G.M.A.T.) & No. of Leonids \\
\hline Nov. 11 & 9.30 to 10.30 & 3 \\
\hline & $\begin{array}{l}\text { Do } \\
9.30 \text { to } 11,30\end{array}$ & 8 \\
\hline$" \Rightarrow 14$ & 9.0 to 10.15 & 7 \\
\hline $\begin{array}{ll}" 15 \\
" 16\end{array}$ & $\begin{array}{l}9.15 \text { to } 10.30 \\
8.45 \text { to } 10.15\end{array}$ & $\begin{array}{r}6 \\
19\end{array}$ \\
\hline
\end{tabular}

The sky was generally hazy.

Mr. Arthur Renshaw, Manchester, writes that at 4.30 a.m. of November 13 he noticed that "in an E.S.E. direction the sky was illuminated by what at first I took to be rockets. . . . A group of people waiting for the first workmen's tramcars were gazing in wonderment. Stars were shooting from left to right and vice versa; in most cases there was a streak of light . . . hanging in the sky, which lasted for several minutes." This account, as regards both the direction in which the meteors were seen and their character, is strangely suggestive of a display of Leonids. If this can be substantiated, it means that the maximum of the shower happened this year at least four days before the usual date-an unprecedented occurrence.

\section{Announcements}

Mr. H. B. WATERs, deputy director of agriculture, Gold Coast, has been appointed director of agriculture, Kenya.

THE twenty-fourth annual exhibition of scientific instruments and apparatus, arranged by the Physical Society, will be held on January 9-11, at the Imperial College of Science and Technology, Imperial Institute Road, South Kensington, S.W.7. The leading manufacturers of scientific instruments will be exhibiting their latest products in the Trade Section. The Research and Experimental Section will contain contributions from most of the important research laboratories in Great Britain, and there will be a special sub-section devoted to experiments of educational interest. The following discourses will be delivered in the evenings at 8 p.m. : January 9, R. S. Whipple, "The Evolution of the Galvanometer" ; January 10, J. Guild, "The Instrumental Side of Colorimetry"; January 11, Sir J. Ambrose Fleming, "The History and Development of the Thermionic Valve". Members of institutions and scientific societies may obtain tickets from their secretaries; tickets may also be obtained direct from the Exhibition Secretary, 1, Lowther Gardens, Exhibition Road, S.W.7. No ticket is necessary on January 11.

Applications are invited for the following appointments, on or before the dates mentioned:-A lecturer in chemistry at the Polytechnic, 309, Regent Street, London, W.1-The Director of Education (Dec. 18). A principal of the Maclagan Engineering College, Moghalpura, Lahore, India-The High Commissioner for India, General Department, India House, Aldwych, London, W.C.2 (Dec. 29). A woman inspector of agricultural education-The Secretary, Ministry of Agriculture and Fisheries, 10 Whitehall Place, London, S.W.I (Jan. 4). A head of the Mechanical Engineering Department in the Liverpool Central Municipal Technical School-The Director of Education, 14 Sir Thomas Street, Liverpool (Jan. 5). An engineering inspector to the Ministry of Health-The Director of Establishments, Ministry of Health, Whitehall, S.W.1 (Jan. 8). A principal of the Yorkshire Training College of Housecraft-The Director of Education, Education Offices, Caiverley Street, Leeds (Jan. 12). A bacteriologist or zoologist to investigate foul brood disease in bees at the Rothamsted Experimental Station-The Secretary, Rothamsted Experimental Station, Harpenden, Herts (Jan. 16). A student assistant in the Economics Department of the Harper Adams Agricultural College, Newport, ShropshireThe Advisory Economist. 